\title{
Long-term maintenance of germlings of Sargassum horneri and $S$. yezoense (Fucales, Phaeophyceae) at low photon irradiance
}

\author{
Nobuyoshi Nanba ${ }^{1)^{*}}$, Ryusuke Kado ${ }^{1)}$, and Hisao Ogawa ${ }^{1)}$ \\ 1) School of Fisheries Sciences, Kitasato University, Sanriku, Ofunato, Iwate 022-0101, Japan \\ *corresponding author (NN) e-mail: nanba@kitasato-u.ac.jp
}

(Received January 29, 2001; Accepted September 11, 2001)

\begin{abstract}
Germlings of Sargassum horneri and S. yezoense were maintained for one year at $1 \mu \mathrm{mol} \mathrm{m}^{-2} \mathrm{~s}^{-1}$ in order to clarify their tolerance to low photon irradiance. All germlings of $S$. horneri maintained for one year showed viable growth after transfer to $27 \mu \mathrm{mol} \mathrm{m} \mathrm{m}^{-2} \mathrm{~s}^{-1}$. The percentage of $S$. yezoense germlings that retained their ability to grow viably began to decrease after 28 weeks, but $17 \%$ still showed a capacity for viable growth after one year of maintenance. These results indicate that germlings produced in a particular season can be maintained throughout the year by keeping them at a low photon irradiance. They would thus always be available for laboratory culture to investigate the effects of environmental factors on their growth and survival, bioassays, and artificial establishment of Sargassum beds. The decrease of viable germlings of S. yezoense may have been caused by a difference in the initial quantity of stored photosynthates used under conditions of very low photon irradiance, because the germlings of $S$. horneri are bigger than those of $S$. yezoense.
\end{abstract}

Key words: Sargassum horneri, Sargassum yezoense, germling, low-irradiance maintenance

\section{Introduction}

Sargassum species, which form dense beds, are widely distributed along tropical and temperate seacoasts, and various Sargassum species characteristically occupy different tidal levels (Yoshida, 1983). Germlings play an important role in the establishment and persistence of Sargassum beds (Deysher and Norton, 1982; Kendrick and Walker, 1991, 1994), and they have been used in the artificial establishment of Sargassum beds (Yamauchi, 1984). They have also been used as bioassay organisms in toxicological tests because of their ecological importance, their ease of laboratory culture, and their sensitivity to marine pollutants and toxicants (Ogawa, 1984; Fletcher, 1992). Therefore, it is important to clarify the effects of environmental factors on the growth and survival of germlings in laboratory culture.

Production of Sargassum germlings in nature is re- stricted to the period of egg release (Yoshida, 1983), and germlings cannot be obtained at other times. It is difficult to obtain germlings as often as desired even during this period, because the germlings are released irregularly, except for some species that display a synchronization of egg release with lunar cycles (Tahara, 1909, 1913; Fletcher, 1980; Okuda, 1981; Nanba and Okuda, 1992; May and Clayton, 1991; Kendrick and Walker, 1994). If germlings could be maintained in the laboratory, they would always be available for laboratory culture to investigate the effects of environmental factors on their growth and survival, for bioassays, and for artificial establishment of Sargassum beds.

Nanba and Okuda (1993) reported that germlings of Sargassum horneri (Turner) C. Agardh scarcely grew under low light intensity and darkness in laboratory culture. However, they remained viable for 6 weeks in such 
conditions and resumed growth when transferred to a sufficient light intensity. Tolerance to several months of darkness in laboratory culture has also been demonstrated for the related genera Halidrys (Moss and Sheader, 1973), Fucus (McLachlan, 1974), and Ascophyllum (Sheader and Moss, 1975). It seems likely, therefore, that Sargassum germlings can be maintained under such conditions for a long period. In this study, germlings of an annual species growing in the subtidal zone, Sargassum horneri, and a perennial species growing from the lower intertidal to upper subtidal zone, S. yezoense (Yamada) Yoshida et T. Konno (Yoshida, 1983), were maintained at a low photon irradiance for one year in order to confirm their ability to remain viable.

\section{Materials and Methods \\ Plant materials}

Sargassum horneri and $S$. yezoense thalli with germlings on their receptacles were collected from Okirai Bay, Iwate Prefecture, Japan, in July and August, 1997. The thalli were transported to $50 l$ laboratory culture tanks filled with filtered seawater and aerated at about $20^{\circ} \mathrm{C}$. After the germlings had been released from the receptacles, they were washed with sterilized seawater.

\section{Experimental procedures}

Twenty to 25 and 19 to 34 vigorous germlings of $S$. horneri and $S$. yezoense, respectively, were placed in each petri dish $(90 \times 15 \mathrm{~mm})$ contained $30 \mathrm{ml}$ PESI medium (Tatewaki, 1966) with $0.5 \mathrm{mg} l^{-1}$ germanium dioxide and $25 \mathrm{mg} l^{-1}$ benzylpenicillin potassium; 45 and 50 dishes of $S$. horneri and S. yezoense, respectively, were used in the present experiments. They were maintained for up to 52 weeks at $20^{\circ} \mathrm{C}, 1 \mu \mathrm{mol} \mathrm{m}^{-2} \mathrm{~s}^{-1}$, and a 12-h light, 12-h dark cycle under white fluorescent tubes. The photon irradiance was measured using a Smart Radiometer/ Photometer Model IL1400A (International Light Inc.). The medium was replaced at a photon irradiance of $<1 \mu \mathrm{mol} \mathrm{m}^{-2}$ $\mathrm{s}^{-1}$ every 2 weeks.

The germlings were measured every 4 weeks. At that time, two dishes were randomly selected for each species and transferred to $27 \mu \mathrm{mol} \mathrm{m}^{-2} \mathrm{~s}^{-1}$. This level of photon irradiance has been shown earlier to be adequate for viable growth (Nanba and Ogawa, unpublished data). After 2 weeks of culture at 27 $\mu \mathrm{mol} \mathrm{m}{ }^{-2} \mathrm{~s}^{-1}$, the germlings were measured. Measurements were based on the germlings in a single randomly chosen petri dish for a given species and treatment, excluding dishes in which contamination of germlings by epiphytes had occurred. All germlings in the petri dish were fixed in $5 \%$ formalin seawater after the percentage of germlings attached to the bottom of the dish had been recorded. The germlings were detached from the dish and recorded using a color video camera. Thereafter, their thallus length and rhizoid area were measured using image analysis software (NIH Image 1.62). Where the thallus had differentiated into a stem and leaves, the length of the stem plus leaves was measured as the thallus length.

\section{Statistics}

Differences between pairs of measurements were analyzed for significance by using the Mann-Whitney U-test. In all statistical analyses, significant differences were established at $p<$ 0.05 .

\section{Results \\ Long-term maintenance of germlings at $1 \mu \mathrm{mol} \mathrm{m} \mathbf{~}^{-2}$ $\mathbf{s}^{-1}$}

The mean initial thallus length $(0.25 \mathrm{~mm})$ and rhizoid area $\left(0.004 \mathrm{~mm}^{2}\right)$ of Sargassum horneri (Fig. 1A) were significantly $(p<0.0001)$ higher than those of $S$. yezoense $\left(0.20 \mathrm{~mm}\right.$ and $\left.0.002 \mathrm{~mm}^{2}\right)$ (Fig. $3 \mathrm{~A}$ ).

All germlings of $S$. horneri remained viable for 52 weeks at $1 \mu \mathrm{mol} \mathrm{m} \mathrm{m}^{-2} \mathrm{~s}^{-1}$. They had a densely pigmented thallus and many filamentous rhizoids (Fig. 1B). The mean thallus length reached only $0.90 \mathrm{~mm}$ after 52 weeks. The mean rhizoid area increased rapidly to $0.109 \mathrm{~mm}^{2}$ by 4 weeks, and all germlings became attached to the bottom of the petri dish. Thereafter, the rhizoid area scarcely changed, from 0.103 to $0.164 \mathrm{~mm}^{2}$, and more than $90 \%$ of the germlings remained attached until the end of low-irradiance maintenance (Fig. 2).

All germlings of $S$. yezoense remained viable for 20 weeks at $1 \mu \mathrm{mol} \mathrm{m}^{-2} \mathrm{~s}^{-1}$ (Fig. 5). Thereafter, however, non-viable germlings began to appear, in which the thalli collapsed (Figs 4A, 5). By 52 weeks, only $37 \%$ of the germlings were viable (Figs $3 \mathrm{~B}, 5$ ). There were no significant differences $(p>0.05)$ in mean thallus length and rhizoid area between the viable and non-viable germlings from 24 to 52 weeks, except for length at 36 and 44 weeks. In these cases, the non-viable germlings were slightly longer $(0.49 \mathrm{~mm}$ after 36 weeks and $0.55 \mathrm{~mm}$ after 44 weeks $)$ than the viable germlings $(0.35 \mathrm{~mm}$ after 36 weeks and $0.42 \mathrm{~mm}$ after 44 weeks) because the thalli of the non-viable germlings swelled (Figs 4A, B). The mean thallus length of total (viable plus non-viable) germlings reached only $0.56 \mathrm{~mm}$ after 52 weeks. The mean rhizoid area of total germlings increased rapidly until 4 weeks, with a value of $0.059 \mathrm{~mm}^{2}$, and $96 \%$ of the germlings became attached to the substratum. Thereafter, the rhizoid area scarcely changed, from 0.059 to $0.078 \mathrm{~mm}^{2}$. During the period of low-irradiance mainte- 

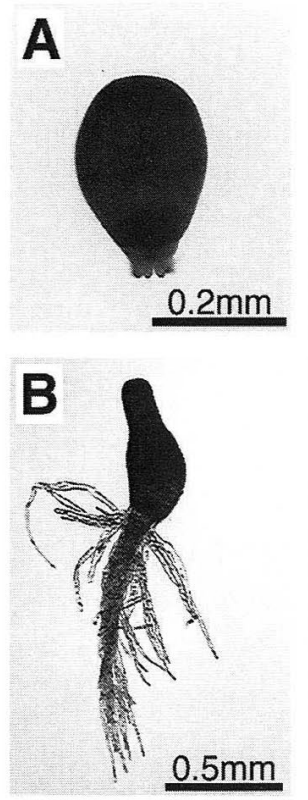
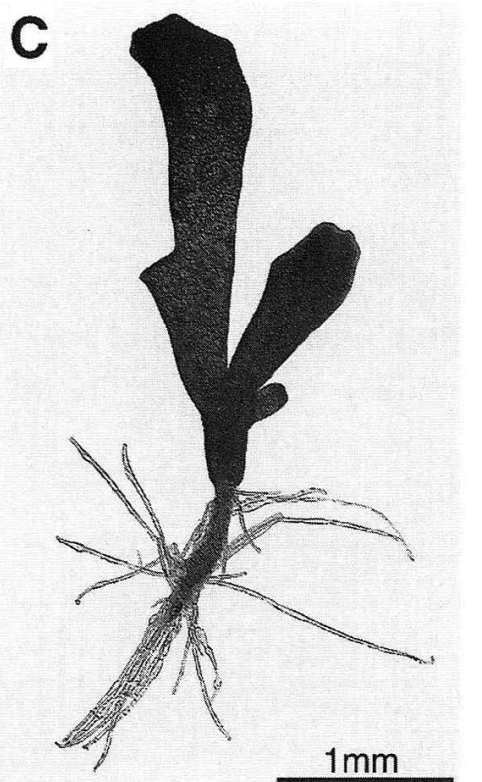

Fig. 1. Viable germlings of Sargassum horneri. A. Germling before culture. B. Germling maintained for 52 weeks at 1 $\mu \mathrm{mol} \mathrm{m} \mathrm{m}^{-2} \mathrm{~s}^{-1}$. C. Germling cultured for 2 weeks at 27 $\mu \mathrm{mol} \mathrm{m}{ }^{-2} \mathrm{~s}^{-1}$ after 52 weeks of maintenance at $1 \mu \mathrm{mol}$ $\mathrm{m}^{-2} \mathrm{~s}^{-1}$
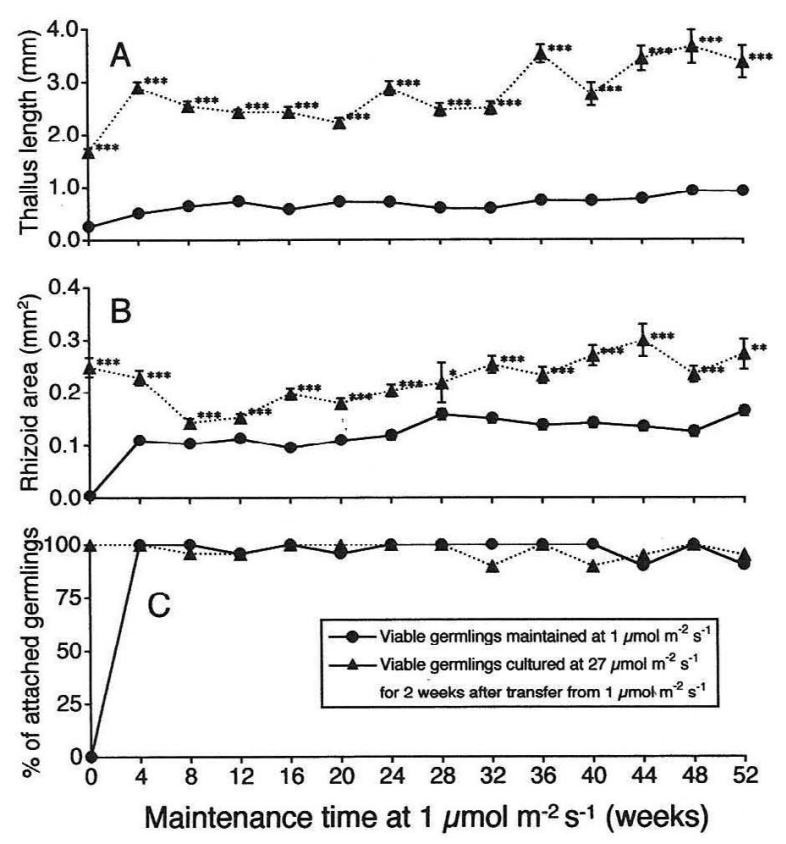

Fig. 2. Thallus length (A) and rhizoid area (B) of germlings, and percentage of attached germlings (C), of Sargassum horneri during the 52-weeks course of the experiment. *, $* *$, and *** are significantly different at $p<0.05, p<0.01$ and $p<0.001$, respectively, from the mean length and area of germlings maintained at $1 \mu \mathrm{mol} \mathrm{m}{ }^{-2} \mathrm{~s}^{-1}$. Data in A and $\mathrm{B}$ are shown as means $\pm \mathrm{SE}$.

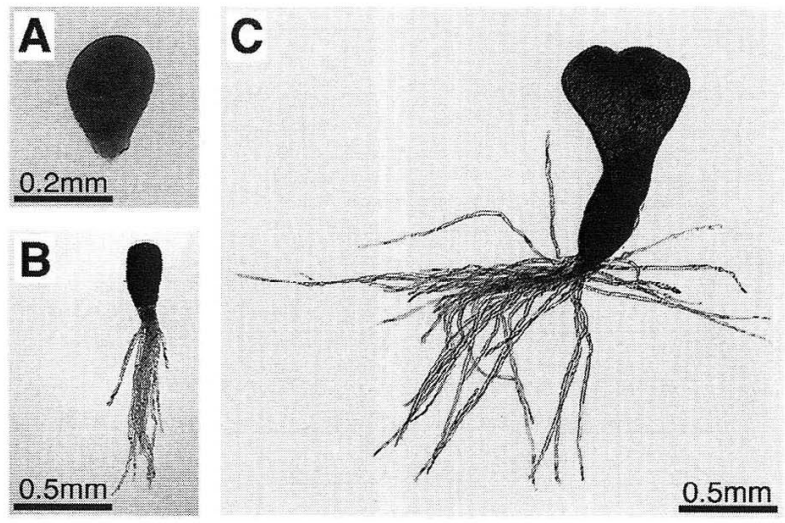

Fig. 3. Viable germlings of Sargassum yezoense. A. Germling before culture. B. Germling maintained for 52 weeks at 1 $\mu \mathrm{mol} \mathrm{m} \mathrm{m}^{-2} \mathrm{~s}^{-1}$. C. Germling cultured for 2 weeks at 27 $\mu \mathrm{mol} \mathrm{m} \mathrm{m}^{-2}$ after 52 weeks of maintenance at $1 \mu \mathrm{mol}$ $\mathrm{m}^{-2} \mathrm{~s}^{-1}$.
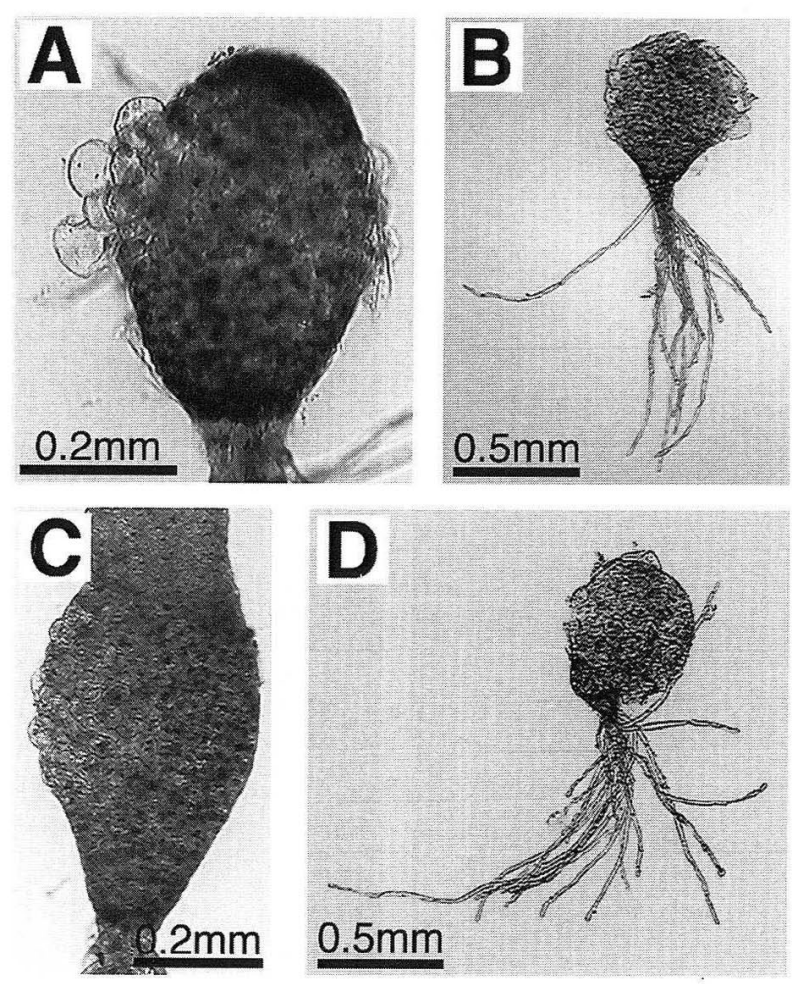

Fig. 4. Non-viable germlings of Sargassum yezoense in which thalli have collapsed. A, B. Germlings maintained for 24 (A) and 52 weeks (B) at $1 \mu \mathrm{mol} \mathrm{m} \mathrm{m}^{-2}$. C, D. Germlings cultured for 2 weeks at $27 \mu \mathrm{mol} \mathrm{m}{ }^{2} \mathrm{~s}^{-1}$ after 28 (C) and 52 weeks (D) of maintenance at $1 \mu \mathrm{mol} \mathrm{m}^{-2} \mathrm{~s}^{-1}$.

nance, more than $80 \%$ of the total germlings remained attached (Fig. 6).

Growth of germlings after transfer to $27 \mu \mathrm{mol} \mathrm{m}^{-2} \mathrm{~s}^{-1}$

All germlings of $S$. horneri cultured at $27 \mu \mathrm{mol} \mathrm{m}^{-2}$ $\mathrm{s}^{-1}$ showed viable growth until 52 weeks of low-irradi- 


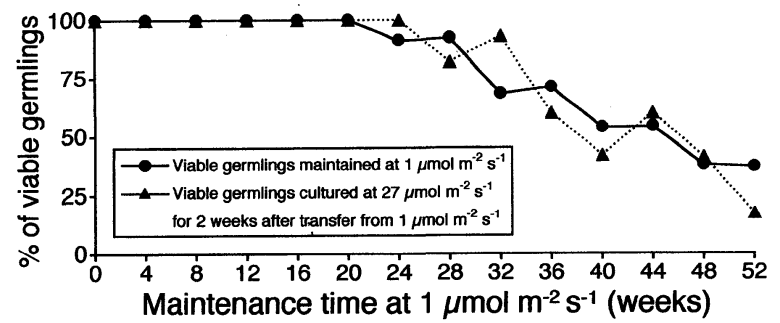

Fig. 5. Percentage of viable germlings of Sargassum yezoense during the 52-weeks course of the experiment.
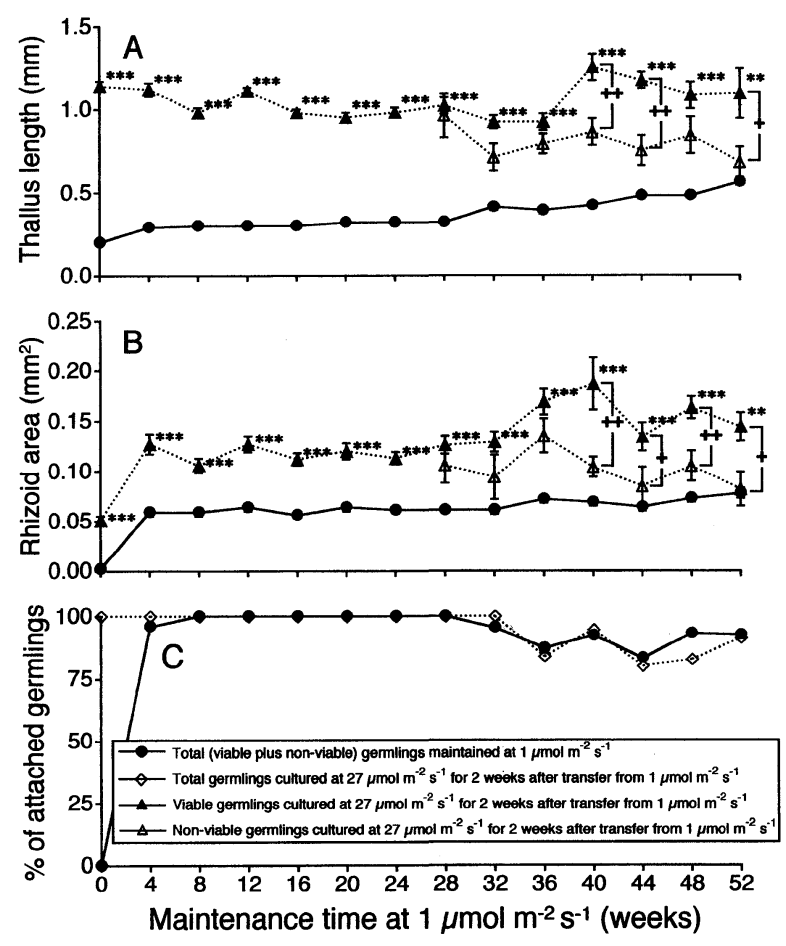

Fig. 6. Thallus length (A) and rhizoid area (B) of germlings, and percentage of attached germlings (C), of Sargassum yezoense during the 52-weeks course of the experiment. $* *$ and $* * *$ are significantly different at $p<0.01$ and $p<$ 0.001 , respectively, from the mean length and area of total (viable plus non-viable) germlings maintained at $1 \mu \mathrm{mol}$ $\mathrm{m}^{-2} \mathrm{~s}^{-1}$. + and ++ are significantly different at $p<0.05$ and $p<0.01$, respectively, between viable and non-viable germlings cultured at $27 \mu \mathrm{mol} \mathrm{m}^{-2} \mathrm{~s}^{-1}$ for 2 weeks after transfer from $1 \mu \mathrm{mol} \mathrm{m}^{-2} \mathrm{~s}^{-1}$. Data in A and B are shown as means $\pm \mathrm{SE}$.

ance maintenance: their thalli differentiated into a stem and leaves, and their rhizoid areas increased (Fig. 1C). The mean thallus lengths $(1.67-3.64 \mathrm{~mm})$ and rhizoid areas $\left(0.143-0.298 \mathrm{~mm}^{2}\right)$ of the cultured germlings were significantly $(p<0.05, p<0.01$, or $p<0.001)$ greater than those before culture $(0.25-0.95 \mathrm{~mm}$ and 0.004-0.164 $\mathrm{mm}^{2}$ ) over the entire period of low-irradiance mainte- nance. More than $90 \%$ of the cultured germlings remained attached until the end of maintenance (Fig. 2).

In $S$. yezoense, all germlings cultured at $27 \mu \mathrm{mol}$ $\mathrm{m}^{-2} \mathrm{~s}^{-1}$ showed viable growth through the first 24 weeks of low-irradiance maintenance (Figs 5,6). Thereafter, non-viable germlings increased, and only $17 \%$ of cultured germlings remained viable after 52 weeks of lowirradiance maintenance (Figs 4C-D, 5). The mean thallus lengths $(0.92-1.25 \mathrm{~mm})$ and rhizoid areas $(0.051$ $0.187 \mathrm{~mm}^{2}$ ) of viable cultured germlings were significantly $(p<0.01$ or $p<0.001)$ greater than those of total germlings (viable plus non-viable) before culture $(0.20$ $0.56 \mathrm{~mm}$ and $0.002-0.078 \mathrm{~mm}^{2}$ ) over the entire period of low-irradiance maintenance. After 2 weeks of culture, there were no differences $(p>0.05)$ in thallus length and rhizoid area between non-viable $(0.71-0.96 \mathrm{~mm}$ and $\left.0.094-0.135 \mathrm{~mm}^{2}\right)$ and viable $(0.92-1.02 \mathrm{~mm}$ and $0.126-$ $0.169 \mathrm{~mm}^{2}$ ) germlings transferred to $27 \mu \mathrm{mol} \mathrm{m}^{-2} \mathrm{~s}^{-1}$ after 28 to 36 weeks of low-irradiance maintenance. Afterwards, the values for non-viable germlings (0.68-0.86 $\mathrm{mm}$ and $\left.0.082-0.104 \mathrm{~mm}^{2}\right)$ were significantly $(p<0.05$ or $p<0.01)$ lower than those of viable germlings (1.08$1.25 \mathrm{~mm}$ and $0.134-0.187 \mathrm{~mm}^{2}$ ), except for mean thallus length of those transferred after 48 weeks. More than $80 \%$ of total (viable plus non-viable) germlings cultured at $27 \mu \mathrm{mol} \mathrm{m}^{-2} \mathrm{~s}^{-1}$ remained attached until the end of maintenance (Fig. 6).

\section{Discussion}

Germlings of Sargassum horneri and $S$. yezoense retained their ability to grow viably and attach to the substratum during 52 weeks at a low photon irradiance of 1 $\mu \mathrm{mol} \mathrm{m} \mathrm{m}^{-2}$. By the easy method of maintenance at low photon irradiance, germlings of the two species can thus be obtained throughout the year for laboratory culture to investigate the effects of environmental factors on their growth and survival, bioassays, and artificial establishment of Sargassum beds.

In Sargassum species, most germlings settle within meters of reproductive adults in their beds (Deysher and Norton, 1982; Kendrick and Walker, 1991, 1995). Furthermore, Kendrick and Walker (1994) reported that small recruits of three Sargassum species appeared throughout the year in Western Australia, yet the release of germlings (as propagules) from the area was highly seasonal. These field observations and our results of this study suggest that the ability of Sargassum germlings to 
attach rapidly and remain viable at low photon irradiance permits them to survive under natural conditions of insufficient light, such as rocky surfaces under dense algal canopies or in crevices.

All germlings of $S$. horneri maintained for one year at a low photon irradiance showed viable growth after transfer to $27 \mu \mathrm{mol} \mathrm{m}^{-2} \mathrm{~s}^{-1}$. In $S$. yezoense, on the other hand, the percentage of germlings remaining viable began to decrease from 28 weeks, and reached $17 \%$ after 52 weeks. This decrease may be caused by differences in the initial quantity of stored photosynthates used under conditions of insufficient light, because the germlings of $S$. horneri are bigger than those of $S$. yezoense. Sargassum horneri is an annual alga and propagates only through germlings (Umezaki, 1984). In contrast, $S$. yezoense is a perennial alga that can propagate through both germlings and vegetative reproduction (Nanba and Ogawa, unpublished data). Therefore, S. horneri may apply its energies to producing big germlings. Furthermore, the ability of Sargassum germlings to survive under insufficient light conditions may be an important factor in determining their vertical distribution in the field, because $S$. yezoense growing in the lower intertidal and upper subtidal zones receives more light than subtidal $S$. horneri does. We plan further studies to investigate the ability of germlings of other Sargassum species that occupy different tidal levels to survive under insufficient light conditions.

\section{References}

Deysher, L. and T. A. Norton. (1982). Dispersal and colonization in Sargassum muticum (Yendo) Fensholt. J. Exp. Mar. Biol. Ecol., 56, 179-195.

Fletcher, R. L. (1980). Studies on the recently introduced brown alga Sargassum muticum (Yendo) Fensholt. III. Periodicity in gamete release and 'Incubation' of early germling stages. Bot. Mar., 23, 425-432.

Fletcher, R. L. (1992). Extended Summaries. SCI Pesticides Group Symposium. In-vitro systems for testing activity, toxicity and metabolism. Pestic. Sci., 35, 291-298.

Kendrick, G. A. and D. I. Walker. (1991). Dispersal distances for propagules of Sargassum spimuligerum (Sargassaceae, Phaeophyta) measured directly by vital staining and venturi suction sampling. Mar. Ecol. Prog. Ser., 79, 133138.

Kendrick, G. A. and D. I. Walker. (1994). Role of recruitment in structuring beds of Sargassum spp. (Phaeophyta) at Rottnest Island, Western Australia. J. Phycol., 30, 200208.
Kendrick, G. A. and D. I. Walker. (1995). Dispersal of propagules of Sargassum spp. (Sargassaceae: Phaeophyta): Observations of local patterns of dispersal and consequences for recruitment and population structure. J. Exp. Mar. Biol. Ecol., 192, 273-288.

May, D. I. and M. N. Clayton. (1991). Oogenesis, the formation of oogonial stalks and fertilization in Sargassum vestitum (Fucales, Phaeophyta) from southern Australia. Phycologia, 30(3), 243-256.

McLachlan, J. (1974). Effects of temperature and light on growth and development of embryos of Fucus edentatus and F. distichus ssp. distichus. Can. J. Bot., 52, 943-951.

Moss, B. and A. Sheader, (1973). The effects of light and temperature upon the germination and growth of Halidrys siliquosa (L.) Lyngb. (Phaeophyceae, Fucales). Phycologia, 12(1/2), 63-68.

Nanba, N. and T. Okuda. (1992). Egg release of five fucalean species in Tsuyazaki, Japan. Nippon Suisan Gakkaishi, 58(4), 659-663 (in Japanese with English abstract).

Nanba, N. and T. Okuda. (1993). Germling growth of Myagropsis myagroides and Sargassum horneri at low light intensity. Nippon Suisan Gakkaishi, 59(8), 12891295 (in Japanese with English abstract).

Ogawa, H. (1984). Effects of treated municipal wastewater on the early development of sargassaceous plants. Hydrobiologia, 116/117, 389-392.

Okuda, T. (1981). Egg liberation in some Japanese Sargassaceae (Phaeophyceae). Proc. 10th Int'l Seaweed Symp., $197-$ 202.

Sheader, A. and B. Moss. (1975). Effects of light and temperature on germination and growth of Ascophyllum nodosum (L.) Le Jol. Estuar. Coast. Mar. Sci., 3, 125-132.

Tahara, M. (1909). On the periodical liberation of the oospheres in Sargassum. Bot. Mag. Tokyo, 23, 151-153.

Tahara, M. (1913). Oogonium liberation and the embryogeny of some fucaceous algae. J. Coll. Sci. Tokyo Imp. Univ., $32,1-13$.

Tatewaki, M. (1966). Formation of a crustaceous sporophyte with unilocular sporangia in Scytosiphon lomentaria. Phycologia, 6(1), 62-66.

Umezaki, I. (1984). Ecological studies of Sargassum horneri (Turner) C. Agardh in Obama Bay, Japan Sea. Nippon Suisan Gakkaishi, 50(7), 1193-1200.

Yamauchi, K. (1984). The formation of Sargassum beds on artificial substrata by transplanting seedlings of $S$. horneri (Turner) C. Agardh and S. muticum (Yendo) Fensholt. Nippon Suisan Gakkaishi, 50(7), 1115-1123.

Yoshida, T. (1983). Japanese species of Sargassum subgenus Bactrophycus (Phaeophyta, Fucales). J. Fac. Sci. Hokkaido Univ. Ser. V (Botany), 13, 99-246. 